\title{
Role of leucocytes in free radical production during myocardial revascularisation
}

\author{
E De Vecchi, R Paroni, M G Pala, G Di Credico, V Agape, C Gobbi, P A Bonini, \\ G Paolini, A Grossi
}

\begin{abstract}
Objective-To evaluate the role of leucocytes in free radical production in patients with depressed or normal ejection fraction undergoing coronary bypass. Design-Two randomised control trials. Setting-Tertiary care centre.

Patients and interventions-In the first study, 22 patients with ejection fractions of $\leqslant 40 \%$ received blood cardioplegic reperfusion with $(n=11)$ or without $(n=$ 11) leucocyte depletion. In the second study, 22 patients with ejection fractions $\geqslant 45 \%$ received either leucocyte depleted $(n=11)$ or blood cardioplegia $(n=11)$.

Main outcome measures-Glutathione, hypoxanthine, and lipid peroxidation products were measured in coronary sinus blood and plasma before aortic cross clamping and at 0,15 , and $30 \mathrm{~min}$ utes after unclamping. Haemodynamic variables and creatine kinase $M B$ isoenzymes were monitored on the first postoperative day. Comparison between treatments was performed on difference $(\Delta)$ between measurements at time 0 and at baseline, and on slopes obtained by fitting measurements after unclamping with a linear regression model.
\end{abstract}

Results-At unclamping no difference in $\Delta$ for plasma glutathione redox ratio (oxidised/total glutathione, \%) was observed between treated and control groups with low ejection fraction $(\Delta=16$ (SD 8.39) and $24(7 \cdot 0)$ redox ratio $\%$, respectively). Baseline value recovery rate (redox ratio $\% / \mathrm{min}$ ) was significantly faster in treated $v$ control patients (slope $-0.912(0.380) v$ $-0.158(0.200), P<0.005$, respectively). Cardiac index showed a trend to greater improvement in the treated group (slope $0.04(0.03) v 0.003(0.002) 1 / \mathrm{min} / \mathrm{m}^{2} / \mathrm{h}, \mathrm{P}<$ 0.02 , treated $v$ controls, respectively). In patients with normal ejection fraction, leucocyte depletion did not result in significant improvement $v$ controls.

Conclusions-Leucocyte depletion seems to provide benefit only in patients with left ventricular dysfunction.

(Heart 1997;77:449-455)

Keywords: myocardial protection; oxidative stress; leucocyte depletion; glutathione

In the past 10 years, a great deal of interest has been focused on the role of leucocytes in gen- erating reperfusion injury in the myocardium. ${ }^{1}$ Activated leucocytes accumulate in reperfused myocardium and are believed to be responsible for capillary plugging, release of arachidonic acid metabolites, activation of complement, and production of oxygen free radicals by the NADPH (reduced nicotinamide adenine dinucleotide phosphate) oxidase pathway. $^{2-4}$ Leucocyte depletion induced by pharmacological agents, antineutrophil antibodies, and leucocyte filters has been shown to be protective in animal models. ${ }^{245}$ However, there is little information about the influence of leucocyte depletion of cardioplegic reperfusate on myocardial metabolism and free radical activity during cardiac surgery in humans.

Reactive oxygen species are produced physiologically in cells during redox reactions, including respiration, but their production may be increased in pathological conditions. ${ }^{6}$ Oxygen free radicals can be cytotoxic by attacking unsaturated fatty acids, starting lipid peroxidation of membranes, and promoting oxidation of protein sulphydryl groups and polypeptide chain scission. ${ }^{6} 7$ Excessive production of free radicals beyond the antioxidant capacity triggers an oxidant stress to the cell. Glutathione, one of the most abundant intracellular antioxidants, acts as cosubstrate for glutathione peroxidase, or as free radical species and lipid peroxide scavenger, with oxidation to the disulphide form. Furthermore, the increase in oxidised glutathione and the inability of the cells to produce reducing equivalents impairs the enzymatic system (glutathione reductase) required for the reduction to reduced glutathione (GSH), thereby enhancing the loss of GSH. Thus the ratio of the oxidised form to total glutathione (redox ratio) plays an important role in the regulation of the redox state of the cells. ${ }^{8}$ Oxidised glutathione is actively transported across the cell membrane to plasma and, together with the redox ratio, may be considered a reliable index of oxidative stress. ${ }^{910} \mathrm{~A}$ well known result of free radical action is peroxidation of membrane polyunsaturated fatty acids, which ultimately results in the production of toxic aldehydes such as malondialdehyde and 4hydroxynonenal. These can react with critical targets, including proteins, forming fluorescent Schiff bases that are easily detectable. ${ }^{611}$ Although lipid peroxidation and antioxidants are non-specific indices of ischaemia-reperfusion injury and can be altered by different processes (such as inflammation), enhanced lipid peroxidation products together with depression of antioxidants is widely accepted 
as a reliable index of oxygen free radical activity. ${ }^{910} 12$

The aim of our study was to test the hypothesis that leucocyte depletion could improve myocardial protection during revascularisation in patients with a low and preserved ejection fraction undergoing cardiopulmonary bypass. To do this we evaluated changes in glutathione status, fluorescent products of lipid peroxidation, and hypoxanthine in coronary plasma. Because erythrocytes are a natural reserve of antioxidants, determinations were also carried out on whole blood samples.

\section{Methods}

PATIENTS

The research was structured in two independent studies on patients undergoing elective myocardial revascularisation. In the first study 22 patients with an ejection fraction $\leqslant 40 \%$ (assessed by a first pass radionuclide angiography) were randomly assigned to receive either blood cardioplegia with leucocyte depletion of cardioplegic reperfusate (LD, $n=11)$ or blood cardioplegia (LC, control group, $\mathrm{n}=$ $11)$. In the second study 22 subjects with an ejection fraction $\geqslant 45 \%$ were randomly allocated into two groups: 11 patients received leucocyte depleted blood cardioplegia (ND); and 11 patients were treated with blood cardioplegia (NC, control group). Subjects with other associated cardiac disease, acute myocardial infarction, or cardiogenic shock, as well as patients undergoing additional surgical procedures (valve replacement, aneurysmectomy), were not entered into the protocol. On the basis of a positron emission tomography (PET) study, patients without viable myocardium were also excluded. Antianginal medication was continued until the day of surgery. All patients were operated on by the same surgical staff. Preoperative data are presented in the table.

The protocol was approved by the ethics committee of our institute and all patients gave informed consent to the study.

SURGICAL PROCEDURE

A standard cardiopulmonary bypass technique was used throughout the study. The same roller pump (Stöckert Instruments, Germany), membrane oxygenator (Compact D703, Dideco, Mirandola, Italy), in-line filter, and cardioplegic prime (Ringer lactate solution $1500 \mathrm{ml}$, mannitol $250 \mathrm{ml}$, and Emagel $100 \mathrm{ml}$ ) were used. In addition to the cannulations for bypass, the retrograde cannula (retroplegia coronary sinus cannula, $14 \mathrm{~F}$, Research Medical, Midvale, Utah, USA) and the antegrade cannula (aortic root cannula, DLP Inc, Grand Rapids, Michigan, USA) were placed in the coronary sinus and the aortic root, respectively. Moderate normovolaemic haemodilution (packed cell volume: $20-25 \%$ ) and moderate hypothermia $\left(28-30^{\circ} \mathrm{C}\right)$ were used. Myocardial revascularisation was achieved, when possible, with bilateral internal mammary arteries plus saphenous vein graft. In patients with a low ejection fraction, ventricular venting was performed by the right superior pulmonary vein. Myocardial protection was achieved by antegrade-retrograde blood cardioplegia according to Buckberg's protocol. ${ }^{13} 14$ Blood cardioplegia was given by a "BuckbergShiley Plus" circuit (Shiley Incorporated, Irvine, California, USA) which supplied oxygenated blood and crystalloid cardioplegia with a $4: 1$ ratio. The cardioplegic delivery time was divided between antegrade in aorta and retrograde in coronary sinus. Cardiac arrest was induced with warm $\left(37^{\circ} \mathrm{C}\right)$ blood substrate enriched cardioplegic solution for five minutes, followed by three minutes of cold induction. Cardioplegic maintenance was similarly assured every 20 minutes for two minutes in both antegrade and retrograde directions in separate ratios. Before release of aortic cross clamping, warm blood cardioplegic reperfusion $\left(37^{\circ} \mathrm{C}\right)$ was given in an antegrade-retrograde manner and through the venous grafts under controlled conditions with a non-beating and empty heart for three minutes $(1.5$ minutes antegrade and 1.5 minutes retrograde).${ }^{13}$ In order to maintain good coronary perfusion at the end of cardiopulmonary bypass, mean arterial pressure was maintained between 70 and $90 \mathrm{~mm} \mathrm{Hg}$ by using inotropic drugs (dopamine) or nitrate infusion.

Cardioplegic reperfusion was leucocyte depleted by using four filters (Leukoseize 2, Dideco, Mirandola, Italy) in parallel on the cardioplegic line; leucocyte depletion of car-

Clinical data. Continuous variables are expressed as medians, 5th and 95th centiles are given in parentheses; discrete variables are expressed as frequency

\begin{tabular}{|c|c|c|c|c|}
\hline & Group LD & Group LC & Group ND & Group NC \\
\hline $\begin{array}{l}\text { Patients (n) } \\
\text { Age (years) } \\
\text { CCS class, II/III/IV } \\
\text { Ejection fraction }(\%) \\
\text { Diseased vessels, } 1 / 2 / 3 / 4 / 5(\mathrm{n}) \\
\text { Distal anastomoses, } 1 / 2 / 3 / 4 / 5(\mathrm{n}) \\
\text { Proximal anastomoses, } 0 / 1 / 2(\mathrm{n}) \\
\text { Bypass time (min) } \\
\text { Cross clamp time (min) } \\
\text { Inotrope use }(>5 \mathrm{gg} / \mathrm{kg} / \mathrm{min})(\mathrm{n}) \\
\text { Intra-aortic balloon pumping (n) } \\
\text { Creatine kinase } \mathrm{MB}, 5 \mathrm{~h} \\
\text { Creatine kinase } \mathrm{MB}, 10 \mathrm{~h} \\
\text { Creatine kinase } \mathrm{MB}, 15 \mathrm{~h}\end{array}$ & $\begin{array}{l}11 \\
63(49 \text { to } 73) \\
0 / 7 / 4 \\
35(27 \text { to } 40) \\
0 / 1 / 8 / 2 / 0 \\
0 / 1 / 8 / 1 / 1 \\
3 / 7 / 1 \\
158(91 \text { to } 188) \\
87(60 \text { to } 115) \\
7 / 11 \\
2 / 11 \\
26(16 \text { to } 40) \\
27(11 \text { to } 49) \\
20(5 \text { to } 73)\end{array}$ & $\begin{array}{l}11 \\
67(56 \text { to } 74) \\
0 / 8 / 3 \\
34(26 \text { to } 40) \\
0 / 2 / 4 / 4 / 1 \\
0 / 4 / 2 / 4 / 1 \\
3 / 5 / 3 \\
160(85 \text { to } 185) \\
90(52 \text { to } 115) \\
8 / 11 \\
2 / 11 \\
27(11 \text { to } 57) \\
27(21 \text { to } 74) \\
19(10 \text { to } 48)\end{array}$ & $\begin{array}{l}11 \\
65(54 \text { to } 76) \\
4 / 3 / 4 \\
57(45 \text { to } 66) \\
1 / 2 / 3 / 4 / 1 \\
1 / 1 / 3 / 4 / 2 \\
3 / 4 / 4 \\
128(104 \text { to } 168) \\
77(60 \text { to } 92) \\
1 / 11 \\
0 / 11 \\
16(1 \text { to } 21) \\
24(10 \text { to } 33) \\
9(7 \text { to } 20)\end{array}$ & $\begin{array}{l}11 \\
61(50 \text { to } 70) \\
5 / 4 / 2 \\
54(45 \text { to } 68) \\
1 / 2 / 5 / 2 / 1 \\
1 / 1 / 5 / 2 / 2 \\
4 / 5 / 2 \\
136(64 \text { to } 158) \\
82(25 \text { to } 116) \\
1 / 11 \\
0 / 11 \\
12(5 \text { to } 35) \\
14(5 \text { to } 32) \\
8(4 \text { to } 10)\end{array}$ \\
\hline
\end{tabular}

CCS class, Canadian Cardiovascular Society system of grading angina; LC, controls with ejection fraction $\leqslant 40 \%$; LD, treated patients with ejection fraction $\leqslant 40 \%$; NC, controls with ejection fraction $\geqslant 45 \% ; \mathrm{ND}$, treated patients with ejection fraction patients with ejection fraction $\leqslant 40 \% ; \mathrm{NC}$, controls with ejection fraction $\geqslant 45 \%$; ND, treated patients with ejection fraction
$\geqslant 45 \%$. Creatine kinase $\mathrm{MB}$ was expressed as $\mathrm{nmol} / \mathrm{ml}$ in $\mathrm{LD}$ and $\mathrm{LC}$ group, as IU/l for ND and ND groups (LC and LD, controls and treated with low ejection fraction; $\mathrm{NC}$ and $\mathrm{ND}$, controls and treated with normal ejection fraction). 
dioplegia implied the use of six leucocyte filters. The efficacy of the depletion technique was assessed by the leucocyte count at the output of the filters (Coulter Counter, model S Plus IV \& V, Instrumentation Laboratory SpA, Milan, Italy). Depletion was considered acceptable when the leucocyte count was less than 150 cells $/ \mathrm{mm}^{3}$.

\section{BIOCHEMICAL EVALUATIONS}

For biochemical measurements blood was withdrawn in cooled heparinised tubes from coronary sinus through the retroplegic cannula before aortic cross clamping, and 0,15 , and 30 minutes after aortic unclamping, and placed in an ice bath.

\section{Glutathione}

Glutathione was measured in blood and plasma immediately after sampling by reversed phase high performance liquid chromatography (HPLC) with pre-column derivatisation as previously described. ${ }^{15}$ Total and total free glutathione concentrations were determined after reduction of disulphides with dithiothreitol; for measurements of the oxidised form the treatment with dithiothreitol was preceded by reaction with $\mathrm{N}$-ethylmaleimide. Samples were automatically derivatised with $o$-phthalaldehyde just before injection. Glutathione disulphide concentration was always expressed as GSH equivalents. Glutathione redox ratio was calculated as the ratio of oxidised to total glutathione and expressed as a percentage.

\section{Hypoxanthine}

Immediately after sampling, blood $(100 \mu \mathrm{l})$ or plasma $(250 \mu \mathrm{l})$ were deproteinised with $500 \mu \mathrm{l}$ of $6 \%$ perchloric acid, neutralised by addition of sodium bicarbonate, and stored at $-20^{\circ} \mathrm{C}$ before HPLC analysis. ${ }^{16}$ The mobile phase consisted of $0.1 \mathrm{~mol} / 1 \mathrm{KH}_{2} \mathrm{PO}_{4}, \mathrm{pH} 6.0$ (buffer A), and buffer A containing $10 \%$ methanol (buffer B). Column (LiChroCart RP18, $250 \times 4 \mathrm{~mm}$, Merck, Darmstadt, Germany) was eluted at $1 \mathrm{ml} / \mathrm{min}$ with buffer A for 15 minutes, then buffer B was increased to $100 \%$ in one minute and held for five minutes; the initial conditions were restored in five minutes.

\section{Lipid peroxidation}

Fluorescent adducts resulting from interaction of terminal aldehydes with amino groups of proteins were determined in plasma according to the method of Ward et al. ${ }^{11}$ Fluorescence was monitored on a LS-3 spectrofluorimeter (Perkin-Elmer, Norwalk, Connecticut, USA) previously calibrated with quinine sulphate.

Blood and plasma measurements were corrected for haemoglobin content or packed cell volume to exclude any dilution effect. ${ }^{17}$

\section{HAEMODYNAMIC AND CLINICAL DATA}

Standard haemodynamic measurements including heart rate, mean arterial pressure, left and right arterial pressure, pulmonary wedge pressure, cardiac output by thermodilution, and the derived cardiac index, were taken in the operating room before sternotomy and at the end of surgery, and in the intensive care unit at $5,10,15,20$, and 25 hours after aortic unclamping. Myocardial isoenzymes of creatine kinase were determined by an immunoenzymatic assay (Stratus, Baxter Diagnostics Inc, Deerfield, Illinois, USA) on peripheral blood 5,10 , and 15 hours after surgery. The use of inotropic agents (dopamine $5 \mu \mathrm{g} / \mathrm{kg} / \mathrm{min}$ ) or intra-aortic balloon pumping, electrocardiographic alteration (as myocardial infarctions evidenced by new $Q$ waves) were also considered in the first postoperative day.

\section{STATISTICAL ANALYSIS}

Statistical analysis was performed by comparing treated subjects $v$ controls in the first trial (LD $v$ LC), and in the second trial (ND $v$ NC).

We focused on two aspects: first we calculated the difference between the measurement at time 0 (immediately after the clamp period) and the measurement at baseline for each subject; then we fitted a linear regression model on the measurements at 0,15 , and 30 minutes after unclamping in each subject. The same analysis was performed for cardiac index and creatine kinase $\mathrm{MB}$ by fitting measurements taken before sternotomy, at the end of surgery, and at $5,10,15,20$, and 25 hours after surgery. Differences between groups (treated $v$ controls), both in $\Delta$ and in slopes, were assessed by the Wilcoxon rank test. Statistical significance was assumed at $\mathrm{P}<0.05$. All analyses were performed using the SAS statistical package for personal computers (SAS Institute, Cary, North Carolina, USA). Slopes and $\Delta$ are expressed as mean (SD).

\section{Results}

Clinical information is summarised in the table. No significant differences were found in any of the preoperative data between treated and the respective control group. No patients died or had electrocardiographic or enzyme changes suggestive for a perioperative myocardial infarct.

\section{GLUTATHIONE}

In patients with a low ejection fraction the calculated $\Delta$ for plasma free oxidised glutathione did not differ significantly between treatments (fig 1A) and a similar trend to normalisation during the following 30 minutes (slope = $-0.053(0.11) v-0.076(0.10) \mu \mathrm{mol} / 1 / \mathrm{min}$, LD $v$ LC) was shown in the two groups (fig 2A). By contrast, leucocyte depletion improved the recovery rate of the redox ratio $\%$ to preischaemic levels (slope $=-0.912$ $(0.380) v-0.158(0.200) \% / \mathrm{min}, \mathrm{P}<0.005$, LD $v$ LC) (fig 2B), while $\Delta$ at unclamping was similar $(\Delta=16(8 \cdot 4) \%$ v $24(7 \cdot 0) \%$, LD $v$ LC, respectively) (fig $1 \mathrm{~B}$ ). In patients with a normal ejection fraction, even though the $\Delta$ showed an increment in plasma oxidised glutathione (fig 1A), there was no marked alteration in the redox ratio \% at unclamping (fig 1B), the value remaining unchanged over the following 30 minutes (fig 2B). During the same period oxidised glutathione normalised 
Figure 1 Differences ( $\Delta$ ) calculated as (time 0 , baseline) measurements in coronary plasma for:

(A) oxidised glutathione;

(B) glutathione redox ratio

$\%$; (C) hypoxanthine;

(D) fluorescent products.

Data are means, error bars

$=S D$. $L C$ and $L D$,

controls and treated with low ejection fraction; $N C$ and ND, controls and

treated with normal

ejection fraction.
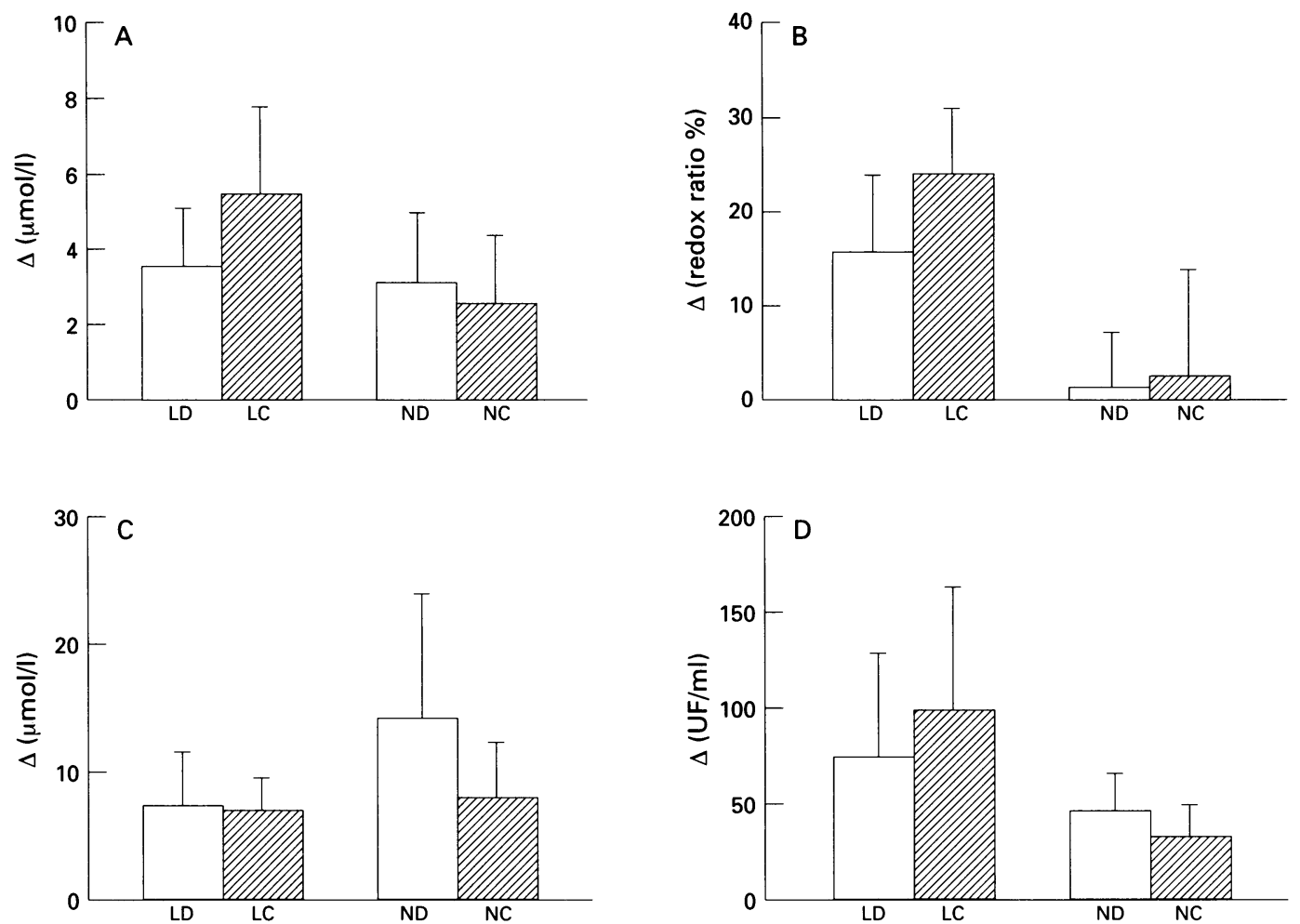

in both groups (slope $=-0.035(0.030) v$ $-0.046(0.060) \mu \mathrm{mol} / 1 / \mathrm{min}, \mathrm{ND} v \mathrm{NC}$ ) (fig 2A). ND patients never showed significant differences compared with controls.

In coronary blood from the LD and LC groups, oxidised glutathione increased after cross clamp removal $(\Delta=0.251(0.162) v$ $0.214(0.200) \mu \mathrm{mol} / 1, \mathrm{LD} v \mathrm{LC})$, with a similar recovery to pre-bypass values (slope: -0.006 $(0.006) \mu \mathrm{mol} / 1 / \mathrm{min}$ for both groups). As a result, heart reperfusion after unclamping was associated with an increment in erythrocyte redox ratio $\%(\Delta=4.02 \quad(2 \cdot 27) \%$ v 3.54 $(3 \cdot 39) \%$, LD $v$ LC), followed by a similar

Figure 2 (A) Oxidised glutathione (GSSG + soluble mixed disulphides) concentration; (B) glutathione redox ratio $\%$ (oxidised/total glutathione $\%$ ) in coronary sinus plasma. In coronary sinus plasma. LD patients;
$\bigcirc$ LC patients; $\triangle N D$ patients; $\triangle N C$ patients ( $L C$ and $L D$, controls and treated with low ejection traction; $N C$ and ND, controls and treated with normal ejection fraction. Data are expressed as means, error bars $=S D$.
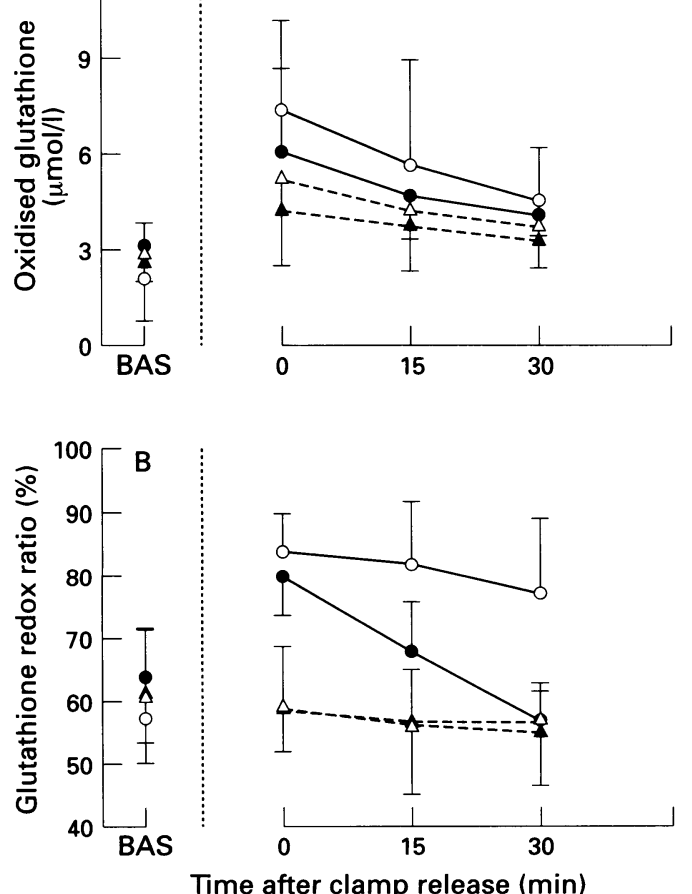

recovery to pre-ischaemic conditions (slope $=$ $-0.12(0.09) v-0.10(0 \cdot 10), \% / \min \mathrm{LD} v$ LC). In ND and NC groups, $\Delta$ for oxidised glutathione did not show sustained oxidation $(\Delta=0.03(0.03) v 0.04(0.04) \mu \mathrm{mol} / 1$, respectively) so that the redox ratio \% was only slightly altered $(\Delta=0.34 \quad(0.29) \% \quad v \quad 0.25$ $(0 \cdot 37) \%, \mathrm{ND} v \mathrm{NC})$.

\section{HYPOXANTHINE}

Hypoxanthine rose in all groups at unclamping, both in blood $(\Delta=13.5(10.4) v 14.3$ (6.38) $\mu \mathrm{mol} / 1, \mathrm{LD} v \mathrm{LC} ; \Delta=17 \cdot 2(11 \cdot 4) v$ $13.9(6.97) \mu \mathrm{mol} / 1, \mathrm{ND} v \mathrm{NC})$ and in plasma (fig 1C). After 30 minutes from cross clamp removal, blood and plasma concentrations (fig 3A) were still altered in all groups. Plasma hypoxanthine was highly variable among ND patients, thus accounting for the high levels observed in the time curve reported in fig $3 \mathrm{~A}$ for this group.

\section{LIPID PEROXIDATION}

Initial values of lipid peroxidation index ranged from 71 to $251 \mathrm{UF} / \mathrm{ml}$ in patients with a low ejection fraction and from 42 to 106 $\mathrm{UF} / \mathrm{ml}$ in those with a normal ejection fraction. Values of $\Delta$ for fluorescent products were similar in plasma of all groups (fig 1D), and in the ensuing 30 minute period the values did not decrease (fig 3B). Although no significant difference between treated and controls was found, levels of fluorescent products were always lower in the LD than in the LC group (fig 3B).

HAEMODYNAMIC AND CLINICAL DATA

The use of inotropic agents (dopamine more than $5 \mu \mathrm{g} / \mathrm{kg} / \mathrm{min}$ ) or intra-aortic balloon pumping was similar in all groups. Creatine kinase $M B$ increased after bypass, reaching a maximum value after 10 hours, with the same 
Figure 3 (A)

Hypoxanthine

concentration; (B)

fluorescent products of lipid peroxidation during cardiopulmonary bypass in coronary sinus plasma. $\bigcirc L D$ patients; $\odot L C$ patients; $\triangle N D$ patients $\triangle N C$ patients (LC and $\triangle D$, controls and treated with low ejection fraction, $N C$ and ND, controls and treated with normal ejection fraction. Data are expressed as means, error bars $=S D$.
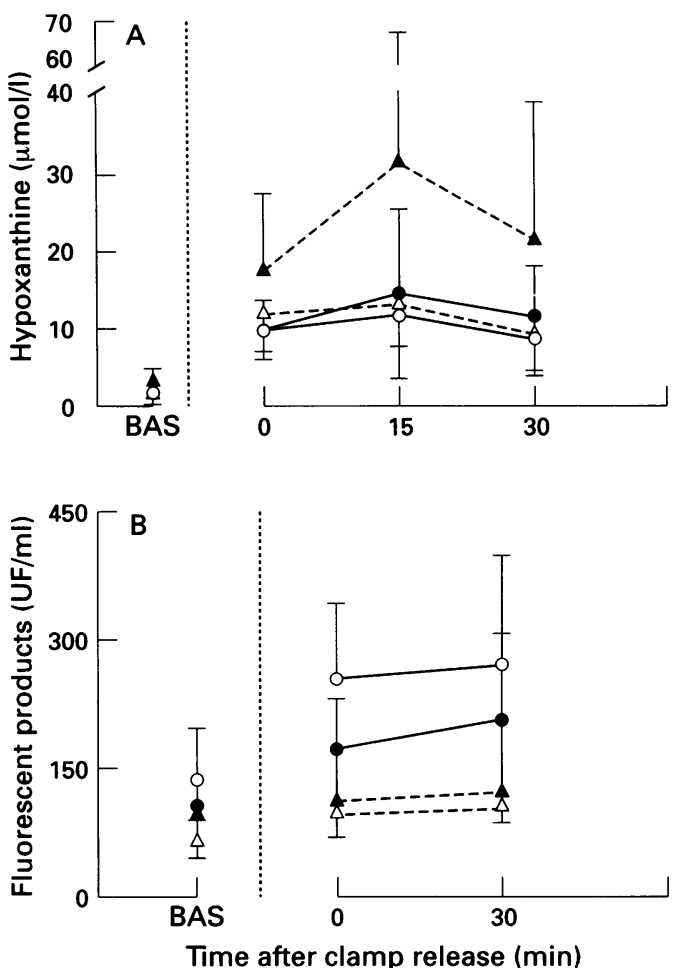

Figure 4 Cardiac index during and after coronary artery bypass grafting (CABG). BAS, before aortic cross clamping; $E N D$, end of coronary artery bypass grafting. - LD patients; $O L C$ patients; $\triangle N D$ patients; $\triangle N C$ patients (LC and $L D$, controls and treated with low ejection fraction; $N C$ and ND, controls and treated with normal ejection fraction. Data are expressed as means, error bars $=S D$.

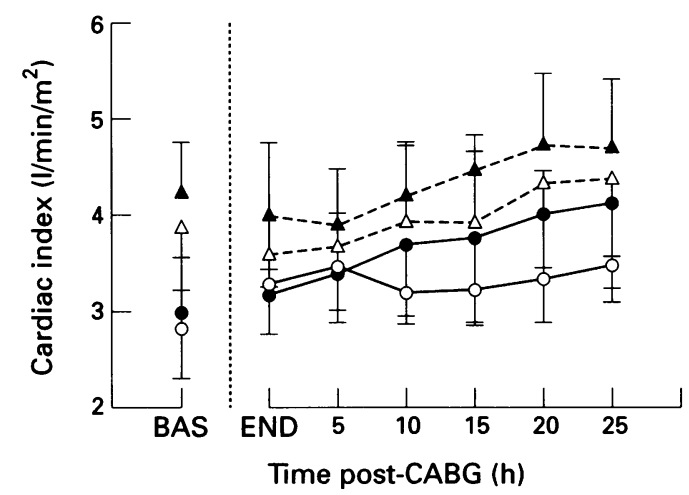

trend in patients with low and normal ejection fractions. No differences were observed between treated patients and controls (table).

In the LD group, the cardiac index improved linearly until it reached a value of $3.99(0.57) \mathrm{l} / \mathrm{min} / \mathrm{m}^{2}$ at 25 hours, the calculated slope of the curve being significantly different from the respective control group (0.04 $(0.03) v 0.003(0.002) 1 / \mathrm{min} / \mathrm{m}^{2} / \mathrm{h}, \mathrm{P}<0.02$, LD $v$ LC) (fig 4). Both treated and control patients with a normal ejection fraction showed a rapid improvement in cardiac index after the operation (slope $=0.03(0.02) \mathrm{l} / \mathrm{min}$ $\mathrm{m}^{2} / \mathrm{h}$ for both ND and NC), with no difference between treatments.

\section{Discussion}

Reperfusion of the ischaemic myocardium is clinically encountered in the thrombolytic treatment of myocardial infarction, coronary angioplasty, bypass surgery, and cardiac transplantation. Although beneficial, uncontrolled reperfusion is associated with tissue damage and functional alteration. Rigid control of reperfusion conditions and reperfusate composition has been shown to be essential for salvaging the previously ischaemic myocardium. ${ }^{18}$

Oxygen free radicals, produced during cardiopulmonary bypass, are widely implicated as the main agents of ischaemia-reperfusion injury. ${ }^{1017} 19-21$ The increased free radical activity in the myocardium results from a reperfusion induced burst in production. This burst overwhelms the capacity of defence mechanisms, because a depletion of radical scavengers occurs during ischaemia. Leucocytes, particularly neutrophils, are recognised as one of the major extracellular sources of oxidant species, although not the only one. ${ }^{22}{ }^{23}$ The initial step in neutrophil accumulation involves interaction between leucocytes and vascular endothelial cells because of their large size, lack of deformability, and the increased expression of neutrophil binding sites. ${ }^{24-26}$ Once bound, neutrophils may be activated by various pathways, including superoxide production by xanthine oxidase, complement activation, and leukotriene B4 production. ${ }^{27-29}$ Neutrophil activation results in greatly enhanced oxygen uptake by cells and in the production of reactive oxygen species. ${ }^{30}$ These considerations provide a rationale for the use of leucocyte depleted blood cardioplegia during bypass surgery.

Previous work has emphasised the value of leucocyte depletion in the long term isolated heart, such as in transplantation, ${ }^{23132}$ but to the best of our knowledge no data are available on the benefits provided over short ischaemic periods in humans. Since patients with left ventricular dysfunction are considered to be at high perioperative risk and require efficient myocardial protection, in the first study we aimed to evaluate the efficacy of leucocyte depletion of cardioplegic reperfusate in this kind of subject. The efficacy of the treatment prompted us to evaluate leucocyte depletion in patients with preserved ejection fraction. Moreover, since during bypass, brief ischaemic periods alternate with short reperfusion, we decided to extend the leucocyte depletion to all phases of cardioplegia.

In patients with low ejection fraction a sustained increment in oxidant species, associated with an increased formation of lipid peroxidation products, suggests the occurrence of oxidative damage. Leucocyte depletion of cardioplegic reperfusion enhanced myocardial protection by promoting a fast recovery of the plasma redox ratio to preischaemic levels and by lowering fluorescent product formation at unclamping. The efficacy of leucocyte depletion was confirmed by the better time response of the cardiac index. We did not find significant differences in inotropic requirements, probably because of the low dose inotropic support routinely used to wean patients from bypass. The study on patients with normal ejection fraction provided evidence of an increase in plasma oxidised glutathione and in fluorescent products of lipid peroxidation. However, these patients were able to balance production of oxidised glutathione, since no appreciable variation in redox ratio was observed over time in blood and plasma. In this class of subjects, leucocyte depletion did 
not seem able to provide additional benefits to blood cardioplegia, even though the postoperative cardiac index appeared to be improved by the treatment.

The higher values of plasma hypoxanthine when leucocyte depletion was performed (LD and ND groups) may support the protective effect of the treatment, since the role of xanthine oxidase in generating oxygen free radicals in reperfused organs is well known. ${ }^{33}$ The slower hypoxanthine catabolism may be related to the lack of histamine release from leucocytes, which is responsible for xanthine oxidase activation. ${ }^{35}$

Our data on plasma glutathione are only apparently at variance with those published by Ferrari and co-workers in $1990,{ }^{10}$ since they achieved myocardial protection by using the $S t$ Thomas' Hospital cardioplegic solution, while we used blood cardioplegia. Blood cardioplegia has been shown to be superior to crystalloid cardioplegia ${ }^{36}$ because blood blends antioxidant benefits with its ability to increase oxygen delivery, prevents ischaemic injury, and limits reperfusion damage. In addition and as described by Buckberg, ${ }^{36}$ before aortic unclamping we performed a brief period of controlled blood cardioplegic reperfusion, which limits myocardial damage. Curello et al have recently suggested that sequestration of leucocytes by the heart during the early phase of reperfusion is unlikely to be related to the rate of oxygen free radical production, since they were not able to observe local neutrophil activation in patients with a normal ejection fraction. ${ }^{37} \mathrm{We}$ found that in patients with low ejection fraction leucocyte depletion of cardioplegic reperfusate improves recovery to preischaemic glutathione redox status in the early phase of reperfusion and improves the mechanical function of the heart in the 24 hours following bypass. These results suggest that leucocytes play a major role in oxidative stress, although activation of the leucocytes is probably not the initiating event.

Although the aim of our study was to assess the efficacy of leucocyte depletion, from our data the response to the ischaemic insult seems to be linked to the baseline ejection fraction. It may be supposed that hearts with left ventricular dysfunction are more susceptible to free radical oxidative damage than normal hearts. However, we cannot rule out the possibility that the lack of benefit observed in patients with a good ejection fraction may be related to a less sustained generation of oxidants than in patients with a poor ejection fraction. To gain a better understanding of the relation between intracellular oxidative processes during bypass surgery and heart function, determination of antioxidants in myocardial biopsies is now in progress.

In conclusion, leucocyte depletion may be advisable in patients with poor heart function, while it appears to provide no benefit in patients with a normal ejection fraction over the routinely used blood cardioplegia.

This work was partially supported by National Research Council, Italy (Grant No 94.02819.CT04). We thank Professor Giuliana Cighetti for her invaluable help in discus- sions on the role of xanthine oxidase and leucocyte depletion, and Mrs Marilena Lomartire for her skilful technical assistance.

1 Lucchesi BR, Mullane KM. Leukocytes and ischemiainduced myocardial injury. Annu Rev Pharmacol Toxicol 1986;26:201-24.

2 Breda MA, Drinkwater DC, Laks H, Bhuta S, Corno AF, Davtyan HG, et al. Prevention of reperfusion injury in the neonatal heart with leukocyte depleted blood. F Thorac Cardiovasc Surg 1989;97:654-65.

3 Wilson IC, Gardner TJ, Di Natale JM, Gillinov AM, Curtis WE, Cameron DE. Temporary leukocyte depletion reduces ventricular dysfunction during prolonged postischemic reperfusion. If Thorac Cardiovasc Surg 1993; 106:805-10.

4 Mullane KM, Read N, Salmon JA, Moncada S. Role of neutrophils in acute myocardial infarction in anaesthetised dogs: relationship to myocardial salvage by antiinflammatory drugs. 7 Pharmacol Exp Ther 1984;228: 510-22.

5 Romson JL, Hook BG, Kunkel SC, Abrams GD, Schork A, Lucchesi BR. Reduction of the extent of ischemi myocardial injury by neutrophils depletion in the dog. Circulation 1983;67:1016-23.

6 Lunec J. Free radicals: their involvement in disease processes. Ann Clin Biochem 1990;27:173-82.

7 Kloner RA, Przylenk K, Whittaker P. Deleterious effects of oxygen radicals in ischemia/reperfusion. Resolved and oxygen radicals in ischemia/reperfusion. Resolv
unresolved issues. Circulation 1989;80:1115-27.

8 Menasche P, Grousset C, Gauduel Y, Piwnica A. A comparative study of free radical scavengers in cardioplegic solutions. F Thorac Cardiovasc Surg 1986;92:264-71.

9 McCoy RN, Hill KE, Ayon MA, Stein JH, Burk RF. Oxidant stress following renal ischemia: changes in the glutathione redox ratio. Kidney Int 1988;33:812-7.

10 Ferrari R, Alfieri O, Curello S, Ceconi C, Cargnoni A, Marzollo $\mathrm{P}$, et al. Occurrence of oxidative stress during reperfusion of human heart. Circulation 1990;81:201-11.

11 Ward PA, Till GO, Hatherill JR, Annesley TM, Kunkel RG. Systemic complement activation, lung injury, and products of lipid peroxidation. $\mathcal{f}$ Clin Invest 1985;76: 517-27.

12 Ogilvie AC, Groeneveld ABJ, Straub JP, Thijs LG. Plasma lipid peroxides and antioxidants in human septic shock. Intensive Care Med 1991;17:40-4.

13 Buckberg GD. Strategies and logic of cardioplegic delivery to prevent, avoid and preserve ischemic and reperfusion prevent, avoid and preserve ischemic and reperf

14 Buckberg GD. Anterograde and retrograde blood cardioplegia to ensure cardioplegic distribution: operative techplegia to ensure cardioplegic distribution: operative tech-
niques and objectives. $\mathcal{F}$ Cardiac Surg 1989;4:216-38.

15 Paroni R, De Vecchi E, Cighetti G, Arcelloni C, Fermo I Grossi A, et al. Total, oxidized and protein bound gluGrossi A, et al. Total, oxidized and protein bound glu-
tathione in blood, plasma and tissue using HPLC with tathione in blood, plasma and tissue using HPLC with o-phthalaldehyde

16 Stocchi V, Cucchiarini L, Magnani M, Chiarantini L, Palma P, Crescentini G. Simultaneous extraction and reverse-phase high performance liquid chromatographic determination of adenine and pyridine nucleotides in human red blood cells. Anal Biochem 1985;146:118-24.

17 Grech ED, Bianes M, Steyn R, Faragher EB, Page RD, Fabri BM, et al. Evidence that continuous normothermic blood cardioplegia offers better myocardial protection
than intermittent hypothermic cardioplegia. Br Heart $\mathcal{f}$ 1995;74:517-21.

18 Allen BS, Okamoto F, Buckberg GD, Bugy H, Young $\mathrm{H}$, Leaf J, et al. Studies of controlled reperfusion after ischemia. XV. Immediate functional recovery after six hours of regional ischemia by careful control of conditions of reperfusion and composition of reperfusate. $f$ thorac Cardiovasc Surg 1986;92:621-35.

19 Lazzarino G, Raatikainen P, Nuutinen M, Nissinen J, Tavazzi B, Di Pierro D, et al. Myocardial release of malTavazzi B, Di Pierro D, et al. Myocardial release of mal-
ondialdehyde and purine compounds during coronary ondialdehyde and purine compounds dur
bypass surgery. Circulation 1994;90:291-7.

20 Coghlan JG, Flitter WD, Clutton SM, Ilsley CDJ, Rees A, Coghlan JG, Flitter WD, Clutton SM, Ilsley CDJ, Rees A,
Slater TF. Lipid peroxidation and changes in vitamin E Slater TF. Lipid peroxidation and changes in vitamin $\mathrm{E}$
levels during coronary artery bypass grafting. $\mathcal{J}$ Thorac levels during coronary artery bypass
Cardiovasc Surg 1993;106:268-74.

21 Menasché $P$, Pasquier C, Bellucci S, Lorente P, Jaillon P, Piwinica A. Deferoxamine reduces neutrophils-mediated free radical production during cardiopulmonary bypass in man. F Thorac Cardiovasc Surg 1988;96:582-9.

22 Westlin W, Mullane KM. Alleviation of myocardial stunning by leukocyte and platelet depletion. Circulation 1989;80:1828-36.

23 Fukushima N, Shirakawa R, Nakata S, Kaneko M, Miyagawa S, Kitagawa S, et al. Effects of terminal cardioplegia with leukocyte-depleted blood on myocardial adenosine triphosphate in heart grafts preserved for 24 hours. Transplant Proc 1992;24:1489-90.

24 Korchak HM, Vienne K, Rutherford LE, Weissman G. Neutrophils stimulation: receptor, membrane and metabolic events. Fed Proc 1984;43:2749-54.

25 Byrne JG, Appleyard RF, Chin Lee C, Couper GS, Scholl FG, Cohn LH. Controlled reperfusion of the regionally ischemic myocardium with leukocyte-depleted blood reduces stunning, the no-reflow phenomenon and infarct size. ₹ Thorac Cardiovasc Surg 1992;103:66-72.

26 Youker K, Entman ML, Taylor AA, Shappel SB, Smith $\mathrm{CW} . \mathrm{H}_{2} \mathrm{O}_{2}$ induced adherence of neutrophils to canine cardiac myocytes is PAF-dependent and involves stimu- 
lation of CD11/CD18 adherence to ICAM-1 [abstract]. Circulation 1990:82:III701.

27 Harlan JM. Leukocytes endothelial interactions. Blood 1985;65:513-25.

28 Ward PA, Hill JH. C5 chemotactic fragment produced by an enzyme in lysosomal granules of neutrophils. Immunol 1970;104:535-43.

29 Mullane KM, Salmon JA, Kraener R. Leukocyte-derived metabolites of arachidonic acid in ischemia-induced myocardial injury. Fed Proc 1987;46:2422-33.

30 Babion BM. The respiratory burst of phagocytes. $f$ Clin Invest 1984;73:599-601.

31 Pearl JM, Drinkwater DC, Laks H, Capouya ER, Gates RN. Leukocyte-depleted reperfusion of transplanted human hearts: a randomized, double-blind clinical trial. $\mathcal{f}$ Heart Lung Transplant 1992;11:1082-92.

32 Pearl JM, Drinkwater DC, Laks H, Stein DG, Capouya ER, Bhuta S. Leukocyte-depleted reperfusion of trans- planted human hearts prevents ultrastructural evidence of reperfusion injury. I Surg Res 1992;52:1-11.

33 Friedl HP, Till GO, Trenz O, Ward PA. Role of oxygen radicals in tourniquet-related ischemia-reperfusion injury of human patients. Klin Wochenschr 1991;69: 1109-12.

34 Kooij A. A reevaluation of the tissue distribution and physiology of xanthine oxidoreductase. Histochem 1994;26:889-915.

35 Friedl HP, Till GO, Trenz O, Ward PA. Roles of histamine, complement, and xanthine oxidase in thermal injury of skin. Am F Pathol 1989;135:203-17.

36 Buckberg GD. Update on current techniques of myocardial protection. Ann Thorac Surg 1995;60:805-14.

37 Curello S, Ceconi C, de Giuli F, Panzali AF, Milanesi B, Calarco $\mathrm{M}$, et al. Oxidative stress during reperfusion of human hearts: potential sources of oxygen free radicals. Cardiovasc Res 1995;29:118-25. 